\title{
IMPLEMENTASI NILAI-NILAI PENDIDIKAN ISLAM DALAM BUDAYA NEMUI NYIMAH DI MASYARAKAT LAMPUNG PEPADUN
}

\author{
Heru Juabdin Sada ${ }^{1}$, Rijal Firdaos ${ }^{2}$, Yunita Sari ${ }^{3}$ \\ herujuabdin@radenintan.ac.id \\ ${ }^{1}$ Universitas Islam Negeri Raden Intan Lampung;
}

\begin{abstract}
This study aims to explain how the values of Islamic education in the culture are found in the community of Lampung Pepadun. The implementation of the culture of Nemui Nyimah in the community of Tiyuh Panaragan is seen in hospitality activities, such as there are procedures or adab-adab visiting and receiving guests. Data analysis techniques used by researchers are data reduction, data display, and conclusion drawing / verification. The results of this study state that: The implementation of the culture of Nemu Nyimah in the Tiyuh Panaragan community can be seen in hospitality activities, such as adab-adab visiting and receiving guests in the community of Tiyuh Panaragan. Based on the results of the Nemu Nyimah Study, it is an explicit culture which means that it cannot be seen in any form, but the culture of Nemu Nyimah is always in any activity or event such as deliberation, forum mulei menganai, yasinan, ngakuk majeu (taking girls), and manjau debingei.
\end{abstract}

Keywords: Culture of Meet Means; Implementation of the Value of Islamic Education

\begin{abstract}
Abstrak
Penelitian ini bertujuan menjelaskan bagaimana nilai-nilai pendidikan islam dalam budaya nemui nyimah di masyarakat lampung pepadun. Implementasi budaya Nemui Nyimah dimasyarakat Tiyuh Panaragan terlihat dalam kegiatan silaturahmi, seperti terdapat tata cara atau adab-adab bertamu dan menerima tamu. Teknik analisa data yang digunakan peneliti yaitu data reduction, data display, dan conclusion drawing/verification. Hasil Studi ini menyatakan bahwa: Implementasi budaya Nemui Nyimah di masyarakat Tiyuh Panaragan dapat dilihat dalam kegiatan silaturahmi, seperti adab-adab bertamu dan menerima tamu dimasyarakat Tiyuh Panaragan. Berdasarkan hasil Studi Nemui Nyimah merupakan budaya yang eksplisit yang artinya tidak dapat dilihat dalam bentuk apapun, tetapi budaya Nemui Nyimah selalu ada dalam kegiatan ataupun acara apapun seperti musyawarah, forum mulei menganai, yasinan, ngakuk majeu (ngambil gadis), dan manjau debingei.
\end{abstract}

Kata Kunci: Budaya Nemui Nyimah; Implementasi Nilai Pendidikan Islam

\section{PENDAHULUAN}

Zaman modern ini banyak generasi bangsa sudah mulai meninggalkan nilai-nilai falsafah hidup yang diwariskan nenek moyang dan memiliki nilai yang sulit ditemukan di zaman modern. Nilai-nilai falsafah hidup merupakan Ideologi bisa diartikan sebagai pedoman hidup suatu bangsa atau kelompok dalam bermasyarakat. Di lain sisi, Pancasila sering juga disebut way of life, weltanschauung, wereldberschouwing, wereld en levens beschouwing, yaitu sebagai pandangan dunia, pandangan hidup, serta petunjuk hidup (Siswanto, Riyanto, \& Bestari, 2014). 
Perubahan-perubahan yang terjadi dewasa ini berjalan sangat cepat. Perubahan itu telah membawa manusia pada kemajuan yang sangat pesat, tetapi juga tidak terlepas dari dampak yang membuat suatu kekacauan, terutama dengan dianutnya sikap hidup yang penuh dengan kebebasan yang tidak mengenal batas. Salah satu hal yang mengacaukan hidup manusia di Indonesia sekarang adalah masalah-masalah yang berhubungan dengan nilai-nilai. Nilai itu sendiri adalah keyakinan yang membuat seseorang bertindak atas dasar pilihannya. Nilai akan selalu berhubungan dengan kebaikan, kebajikan, keluhuran budi, dan akan menjadi sesuatu yang dihargai dan dijunjung tinggi serta dikejar oleh seseorang sehingga ia merasakan adanya suatu kepuasan, karena sering terjadi khususnya prilaku kehidupan yang tidak menghiraukan ajaran yang berlaku dalam Islam dan budaya hidup manusia yang tidak memiliki pandangan ataupun tuntunan dari ajaran Islam, contohnya pendidikan Islam.

Pendidikan Islam adalah suatu sistem pendidikan yang mencakup seluruh aspek kehidupan yang dibutuhkan oleh hamba Allah sebagaimana Islam telah menjadi pedoman bagi seluruh aspek kehidupan manusia, baik dunia maupun ukhrawi (Arifin, 2011). Menurut Achmadi, pendidikan Islam diartikan sebagai semua usaha pemeliharaan dan mengembangkan fitrah yang asli manusia dan sumberdaya yang ada pada manusia menuju terbentuknya manusia sempurna, yakni terbembentuk manusia yang beriman dan bertakwa serta memiliki berbagai kemampuan yang teraktualisasi dalam hubungannya dengan Allah Swt. dengan sesama manusia dan alam sekitarnya (Achmadi, 2005). Proses pendidikan dapat terbentuk melalui pendidikan baik ditingkat formal, non formal ataupun informal. Dengan kata lain pendidikan terjadi di sekolah, masyarakat, dan keluarga. Dalam konteks ini yaitu pendidikan Islam yang terjadi dimasyarakat yang berarakar pada budaya.

Pendidikan Islam yang berakar pada budaya yaitu pendidikan Islam yang tidak meninggalkan akar-akar sejarah, Maka dari itu dengan model pendidikan Islam yang berakar pada budaya, diharapkan dapat membentuk manusia yang mempunyai kepribadian, harga diri, percaya diri berdasarkan budaya sendiri yang akan menjadi warisan dari nenek moyang dan bukan budaya bangsa lain. Tradisi masyarakat Lampung yang telah berlaku secara turun-temurun sikap hidup suka membantu, tolongmenolong (gotong royong) antar sesamanya, itu bukanlah hal asing, walaupun kenyataan ini di era modern yang masih nampak kental sekali dalam kehidupan 
masyarakat pedesaan, sedangkan di kalangan masyarakat di perkotaan yang heterogen sudah nampak agak mengendor, dengan berbagai alasan karena kesibukan dan lain-lain (Sarbini \& Khalik, 2010). Sungguh sangat disayangkan budaya itu tidak dilestarikan dan dikembangkan. Oleh karena itu peneliti bahasa ibu, majelis penyimbang adat Lampung dan pemerhati bahasa daerah memikirkan bahasa dan budaya lampung jangan sampai punah (Roveneldo, 2017).

Nemui Nyimah dalam konteks kehidupan bermasyarakat, diartikan bertamu atau silaturahmi. Silaturahmi di masyarakat kita sering diartikan sebagai kegiatan kunjungmengunjungi, namun bukan itu makna silaturahmi sesungguhnya. Silaturahmi bukan hanya ditandai dengan saling berbalas salam tangan atau memohon maaf belaka. Bila mencermati dari asal katanya, yakni shilat atau washl yang berarti menyambungkan atau menghimpun, dan ar-rahim yang berarti kasih sayang, maka silaturahmi diartikan sebagai menghubungkan kasih sayang antar sesama. Silaturahmi juga bermakna tolong menolong, bertutur kata sopan santun, menghubungkan mereka yang sebelumnya terputus hubungan atau interaksi, dan memberi sesuatu dengan tidak mengharapkan imbalan.

Dapat diketahui bahwa persoalan yang sangat mendasar adalah banyaknya masyarakat Tiyuh Panaragan yang belum mengetahui implementasi nilai-nilai pendidikan Islam dalam budaya Nemui Nyimah di masyarakat Tiyuh Panaragan cenderung terkikis dari kehidupan masyarakat akibat pengaruh budaya dari luar, Sedangkan nilai-nilai yang terkandung dalam budaya Nemui Nyimah merupakan nilainilai yang sangat fundamental di kehidupan masyarakat sehari-hari.

Beberapa penelitian mengenai adat kebiasaan suatu masyarakat, khususnya kebudayaan masyarakat Lampung tentang Piil Pesenggiri (Amaliah, Sariyatun, \& Musaddad, 2018; Irianto \& Margaretha, 2011; Juwita, Cahyono, \& Jazuli, 2017; Kesuma \& Cecilia, 2017; Kurniawan, 2017; Minandar, 2018; Muzakki, 2017; Pairulsyah, 2013; Yusuf, 2010), dan budaya nemui nyimah (Hidayat, 2014) serta penelitian sebelumnya juga ada yang membahas tentang nilai-nilai islam yang berhubungan dengan budaya lampung (Nurdin, 2009; Yusuf, 2016). Namun, masih jarang ditemukan secara khusus yang mengkaji tentang budaya nemui nyimah. Maka, disini penulis ingin meneliti Bagaimana Implementasi Nilai-Nilai Pendidikan Islam Dalam Budaya Nemui Nyimah Di Masyarakat Lampung Pepadun?. Pada Studi 
sederhana ini diharapkan masyarakat Tiyuh Panaragan dan masyarakat suku lampung pada umumnya dapat melestarikan budaya nemui nyimah dalam kehidupan bermasyarakat sehari-hari.

\section{METODE PENELITIAN}

Studi ini termasuk Studi lapangan atau yang disebut dengan field research. Menurut M. Iqbal Hasan Penelitian lapangan (field research), yaitu Studi yang langsung dilakukan di lapangan atau pada responden (Sugiyono, 2010). Dalam Studi ini, peneliti menggunakan metode Studi yang bersifat deskriptif kualitatif. Penelitian yang bersifat deskriptif kualitatif adalah Penelitian yang memberikan gambaran atau uraian atau suatu keadaan dengan sejelas mungkin mengenai objek, baik berupa nilai-nilai budaya manusia, nilai karya seni, kelompok tertentu, pristiwa, atau objek budaya lainnya. Studi diupayakan untuk mengamati permasalahan secara sistematis dan akurat mengenai fakta dan sifat objek tertentu. Studi deskriptif ditunjukkan untuk memaparkan, menggambarkan fakta-fakta berdasarkan cara pandang atau berfikir tertentu (Fathurahman, 2011).

Studi deskriptif mempunyai dua ciri sebagai berikut, (1) berhubungan dengan keadaan yang terjadi saat itu, (2) menguraikan satu variabel saja atau beberapa variabel, namun diuraikan satu persatu. Pada umumnya Studi deskriptif ini menggunakan observasi sebagai metode pen.gumpulan data (Kountour, 2004). Bog dan Tailor yang dikutib oleh Lexy J. Moleong mendefinisikan Studi kualitatif adalah sebagai prosedur Studi yang menghasilkan data deskriptif yang berupa kata-kata atau lisan dari orang dan perilaku yang diamati (Moleng, 1977).

Adapun sumber data yang diambil oleh peneliti dalam Studi ini adalah sumber data utama, Suharsimi Arikunto mengungkapkan bahwa yang dimaksud sumber data dalam Studi adalah subyek dari mana data diperoleh (Arikunto, 2002). Sumber data utama yang berupa kata-kata dan tindakan atau pengamat, serta sumber data tambahan yang berupa dokumen-dokumen, selebihnya adalah data tambahan yaitu sumber data tertulis, foto dan sebagainya. Sehingga peneliti memperoleh beberapa data yang dimanfaatkan dalam Studi ini meliputi: sumber data utama (primer), Moleong mengatakan bahwa sumber data utama adalah sumber data yang diambil peneliti melalui kata-kata dan tindakan atau pengamatan, meliputi: proses pengamatan implementasi nilai-nilai pendidikan Islam di masyarakat Tiyuh Panaragan. Sumber 
data tambahan (sekunder), Data sekunder dalam bahasa Inggris disebut Secondary Resources, yaitu data yang diperoleh dari tangan kedua, artinya tidak langsung dari sumber (Sugiyono, 2005). Adapun data sekunder dalam Studi ini, didapat melalui bukubuku, jurnal atau makalah, serta literatur lainnya yang berkaitan dengan nilai-nilai pendidikan Islam dalam budaya Nemui Nyimah.

Peneliti menggunakan metode Studi yang bersifat deskriptif kualitatif. Studi yang bersifat deskriptif kualitatif adalah Studi yang memberikan gambaran atau uraian atau suatu keadaan dengan sejelas mungkin mengenai objek, baik berupa nilai-nilai budaya manusia, nilai karya seni, kelompok tertentu, pristiwa, atau objek budaya lainnya. Untuk mengumpulkan data-data dilapangan yang diperlukan dalam Studi ini digunakan beberapa metode, yaitu sebagai berikut: metode observasi, metode wawancara dan metode dokumentasi.

Analisis data dalam Studi kualitatif, dilakukan pada saat pengumpulan data berlangsung, dan setelah selesai pengumpulan data dalam periode tertentu. Data diperoleh dari berbagai sumber dengan menggunakan teknik pengumpulan data yang bermacam-macam. Miles dan Huberman mengemukakan bahwa aktivitas dalam analisis data kualitatif dilakukan secara interaktif dan berlangsung secara terus-menerus sampai tuntas, sehingga datanya sudah jenuh. Dalam menganalisis data yang diperoleh dari metode pengumpulan data, maka peneliti menggunakan teknik analisis deskriptif kualitatif. Teknik analisis deskriptif kualitatif, peneliti gunakan untuk menguraikan, menuturkan, menafsirkan data yang diperoleh dari metode pengumpulan data. Analisis data kualitatif dilakukan secara interaktif dan berlangsung secara terus menerus sampai tuntas. Aktivitas dalam analisis data, yaitu data reduction, data display, dan conclusion drawing/verification.

\section{HASIL PENELITIAN DAN PEMBAHASAN}

Masyarakat Lampung memiliki budaya dan pandangan hidup yang sampai sekarang masih dilestarikan, seperti masyarakat adat Lampung di Panaragan yang masih melestarikan falsafah adat Lampung yaitu Piil Pesenggiri sebagai pedoman masyarakat Tiyuh Panaragan. Piil Pesenggiri merupakan kebudayaan yang telah melekat dan menjadi pedoman masyarakat Tiyuh Panaragan yang berisi nilai-nilai dan tujuan hidup yang belum diketahui banyak orang. Di dalam Piil Pesenggiri memiliki empat unsur yakni : pertama Bejuluk beadek bagi masyarakat Lampung memiliki makna pemberian 
gelar, untuk meningkatkan kesempurnaan hidup. Bejuluk beadek mencerminkan kerendahan hati untuk saling menghormati baik dalam keluarga maupun masyarakat. Kedua Nemui Nyimah bagi masyarakat Lampung memiliki makna adab-adab dalam silaturahmi seperti keharusan bertutur kata sopan santun dalam bertamu dan menerima tamu, sikap santun menghormati tamu, ramah dan terbuka kepada setiap orang, bukan hanya kepada tamu, tetapi kepada seluruh masyarakat. Ketiga Nengah Nyappur bagi masyarakat Lampung memiliki makna suka bergaul dan bermasyarakat dalam kegiatan acara apapun. Setiap masyarakat Lampung dituntut untuk selalu mampu berkomunikasi dengan lingkungan ataupun orang lain sebagai makhluk sosial. Keempat Sakai Sambaian bagi masyarakat Lampung memiliki makna saling tolong menolong, berjiwa sosial, dan bergotong royong antara kerabat dekat, tetangga maupun orang lain. Masyarakat Lampung juga harus pandai menjalin kerjasama dengan lingkungan masyarakat seperti mengeluarkan ide-ide pemikiran.

Piil Pesenggiri bagi masyarakat Lampung, dikenal dengan falsafah hidup. Dalam penjelasan di atas yang akan menjadi fokus Studi yaitu budaya Nemui Nyimah. Dimana terdapat nilai-nilai di dalamnya, antara lain sifat keterbukaan masyarakat Lampung seperti suka memberi, tolong menolong dengan ikhlas serta bermurah hati terhadap sesama manusia. Nemui Nyimah yang merupakan salah satu dari unsur Piil Pesenggiri yang masih diterapkan di Tiyuh Panaragan. Berdasarkan hasil Studi, Nemui Nyimah merupakan budaya yang eksplisit yang artinya tidak dapat dilihat dalam bentuk apapun, tetapi budaya Nemui Nyimah selalu ada dalam kegiatan ataupun acara apapun yang terdapat nilai-nilai budaya Nemui Nyimah di dalamnya.

Salah satu unsur dari Piil Pesenggiri yakni Nemui Nyimah yang diterapkan oleh masyarakat Tiyuh Panaragan dapat dilihat dari hal-hal berikut. Musyawarah, kegiatan musyawarah selalu dilakukan oleh masyarakat Tiyuh Panaragan yang di sertai tokoh adat, tokoh Agama dan tokoh masyarakat ketika ada acara-acara di Tiyuh Panaragan. Misalnya acara kegiatan untuk memeriahkan hari kemerdekaan Republik Indonesia, acara untuk menyambut bulan suci Ramadhan bukan hanya itu saja, musyawarah dalam rangka gotong royong membersihkan rumput-rumput dilingkungan Tiyuh Panaragan. Hal tersebut dilakukan agar memiliki jiwa sosial yang peduli akan lingkungan sekitar. Walaupun tidak semua melaksanakannya tetapi budaya ini tetap diterapkan. Dalam gotong-royong tersebut dapat menjalin silaturahmi dan keakraban antara bapak-bapak 
yang di masyarakat Tiyuh Panaragan. Kegiatan tersebut menunjukan adanya nilai pendidikan Islam yakni nilai tolong menolong, kekeluargaan dan kerukunan. Forum Mulei Menganai (bujang gadis), kegiatan pemuda-pemudi di Tiyuh Panaragan agar keakraban antara bujang gadis terjaga dan sealalu bisa berkumpul dalam hal positif, misalnya memeriahkan Tiyuh seperti menyambut tahun baru, merayakan hari kemerdekaan Republik Indonesia, menyambut bulan suci Ramadhan agar persamaan dan persatuan tetap terjaga. Kegiatan tersebut menunjukan adanya nilai pendidikan Islam yakni nilai persatuan dan kerukunan. Yasinan, kegiatan acara rutin yang dilakukan setiap malam jum'at bergilir di rumah masyarakat khusus bapak-bapak untuk menjalin tali silaturahmi antara bapak-bapak yang ada di Tiyuh Panaragan. Kegiatan tersebut menunjukan adanya nilai pendidikan Islam yakni nilai religius dan nilai tolong menolong. Ngakuk Majeu, dalam acara tersebut jika di rumah lelaki atau bujang ngakuk majeu (ngambil gadis/calon pengantin wanita), jadi seluruh masyarakat Tiyuh berkunjung silaturahmi untuk mengetahui majeu (calon pengantin wanita). Biasanya tuan rumah memberikan suguhan-suguhan makanan ringan yang sesuai dengan kemampuan seperti halnya yang diajarkan nenek moyang masyarakat Lampug itu sendiri. Sikap tersebut menunjukan adanya nilai pendidikan Islam yakni nilai kepedulian dan sopan santun. Manjau Debingei, kegiatan tersebut dilakukan setiap satu minggu sekali.

Kegiatan Manjau Debingei dilakukan oleh muli menganai atau pemuda-pemudi untuk berkumpul di suatu tempat untuk mempererat tali silaturahmi antara pemudapemudi yang ada di Tiyuh Panaragan. Kegiatan tersebut menunjukan adanya nilai pendidikan Islam yakni nilai sopan santun dan nilai kekeluargaan. Kegiatan Nemui Nyimah di atas terdapat nilai-nilai pendidikan Islam yang selalu diterapkan di Tiyuh Panaragan meskipun ada beberapa masyarakat yang tidak aktif dalam kegiatan tersebut karena alasan sibuk dan lain-lain. Melalui kegiatan tersebut dapat mempertahankan nilai-nilai yang terdapat dalam budaya Nemui Nyimah, misalnya menjaga kesopanan dalam tutur kata dan bersikap terhadap sesama makhluk sosial. Dilihat dari hasil observasi Masyarakat Tiyuh Panaragan masih sangat ketergantungan terhadap sesama, dimana masyarakatnya masih saling membutuhkan sebagai makhluk sosial tidak dapat dipungkiri, sifat tolong menolong, bermurah hati lah yang melekat kuat menjadi identitas masyarakat Tiyuh Panaragan. Nemui Nyimah adalah sikap pemurah, buka 
tangan, suka memberi dan menerima sesuai dengan kemampuan yang dimiliki. Masyarakat Panaragan masih memegang teguh budaya harga diri yang salah satunya budaya Nemui Nyimah. Masyarakat di Tiyuh Panaragan sangat erat kesetiakawanan sosial, kepedulian, sikap tersebut terlihat saat mereka berhubungan dengan tetangga dan alam sekitar dilingkungan masyarakat. Dalam budaya Nemui Nyimah penerapannya bisa dilihat saat bersilaturahmi. Begitu banyak manfaat bagi kita jika sesuai dengan ajaran Islam.

Silaturahmi yang di utamakan niatan karena Allah. Niatan berhubungan dengan keikhlasan hati yang menumbuhkan betapa pentingnya sikap peduli, tolong menolong, ramah terhadap sesame. Nemui Nyimah bagi masyarakat Tiyuh Panaragan adalah pedoman dalam bertindak dan bersikap dalam kehidupan sehari-hari terhadap semua orang di lingkungan masyarakat, seperti bertutur kata yang sesuai dengan akhlak yang di ajarkan Islam. Di dalam menerima tamu (temui) di perlakukan seperti raja walaupun tamu (temui) tersebut berbeda suku dan agama. Sebaliknya jika kita berkunjung kepada keluarga atau tetangga kita harus sopan santun sesuai dengan adab-adab bertamu yang di ajarkan oleh Islam, jika diberi suguhan yang tak sesuai selera ciciplah walau hanya sedikit, karena yang dikhawatirkan akan menyinggung perasaan si tuan rumah bila suguhan tidak di makan, saling menjaga perasaan. Al-Qur'an pun menjelaskan bahwa seorang tamu itu raja dan harus dihormati. Karena banyak manfaatnya mempererat tali silaturahmi. Adapun kisah nabi yang menceritakan tentang menghormati tamu dalam surah Adz-Dzariyat ayat 26-27.

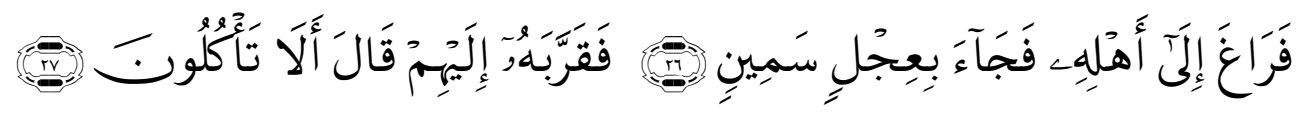

Artinya : "Maka dia pergi dengan diam-diam menemui keluarganya, kemudian dibawanya daging anak sapi gemuk, Lalu dihidangkannya kepada mereka. Ibrahim lalu berkata: "Silahkan anda makan". (Q.S. Adz-Dzariyat : 26-27)

Islam mengajarkan kita untuk selalu bersilaturahmi, jangan sampai memutus hubungan persaudaraan antara sesama manusia. Silaturahmi adalah kunci kebahagiaan hidup, dengan bersilaturahmi maka pintu rezeki akan dibukakan oleh Allah. Menurut Zulkifli Nemui Nyimah adalah sopan santun dalam bertamu dan menerima tamu ke rumah keluarga ataupun orang lain, dan menghargai pendapat orang lain, serta saling 
tolong-menolong antar keluarga dan tetangga bahkan semua orang yang ada di lingkungan masyarakat Tiyuh Panaragan.

Nemui Nyimah dalam penerapan sehari-hari seperti tolong menolong, tolong menolong di sini bukan hanya yang dimaksud materi saja, tetapi lebih ke musyawarah mufakat, sumbangsih pemikiran terlihat ketika ada acara-acara hajatan, pernikahan misalnya. Adat istiadat masyarakat Tiyuh Panaragan, masih kental kekerabatannya walaupun ada masyarakat yang mulai tidak menjalankan tatacara ataupun adat yang berlaku di masyarakat Tiyuh Panaragan. Misalnya dalam acara pernikahan, biasanya ada kegiatan perkumpul bapak-bapak ataupun bujang gadis setiap malam menjelang acara tersebut, tetapi ada masyarakat yang tidak ikut atau ikut andil serta meramaikan karena alasan sibuk dan lain-lain.] Masyarakat Tiyuh Panaragan berpandangan bahwa Nemui Nyimah adalah tata cara dalam bersilaturahmi, seperti ramah tamah dalam menerima tamu, bersikap sopan santun, selain itu dalam menerima tamu diberikan suguhan yang sesuai dengan keadaan tanpa dipaksakan, dan tamu juga diperlakukan sebagai raja. Masyarakat Tiyuh Panaragan saling tolong menolong, ramah tamah, terlihat dalam acara atau hajatan. Masyarakatnya ikut serta tanpa di minta oleh pemilik hajat.

Nemui Nyimah berarti silaturahmi atau pun tata cara bertamu dan menerimah tamu dengan cara sopan santun, ramah tamah, dalam lingkungan masyarakat Lampung. Karena pada prinsipnya adab-adab bertamu dan menerima tamu harus sesuai dengan ajaran Islam, berikut implementasi budaya Nemui Nyimah dimasyarakat Tiyuh Panaragan dapat dilihat dalam kegiatan silaturahmi, yaitu Tatacara bertamu dan menerima tamu; Bertamu ataupun menerima tamu dimasyarakat Tiyuh Panaragan bukanlah hal yang asing, bertamu sudah menjadi kebiasaan di Tiyuh Panaragan. Adabadab bagi penerima tamu (tuan rumah) dan orang yang bertamu. Diantara adab-adab dalam bertamu di masyarakat Tiyuh Panaragan adalah: pertama Masyarakat Tiyuh Panaragan harus berniat ikhlas karena Allah untuk menyambung tali silaturahmi. Alangkah baiknya jika membawa buah tangan untuk menyenangkan tuan rumah. Kedua Mengucap salam dan menjawab salam, lafal salam mengandung arti semoga keselamatan dan kasih sayang Allah serta kebaikan terlimpah kepada kalian. Oleh karena itu ketika bertamu kita mengucapkan salam, bukan hanya berkunjung kerumah sanak saudara saja tetapi mengucapkan salam disunahkan juga ketika bertemu dengan 
saudara sesama muslim. Menjawab salam merupakan suatu kewajiban, Allah berfirman dalam Al-Qur'an Surah An-Nisa ayat 86.

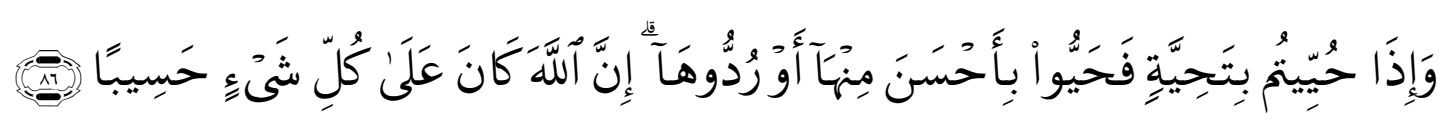

Artinya : "Apabila kamu diberi penghormatan dengan sesuatu penghormatan, maka balaslah penghormatan itu dengan yang lebih aik dari padanya, atau balaslah penghormatan itu (dengan yang serupa). Sesungguhnya Allah memperhitungkan segala sesuatu”. (Q.S. An-Nisa: 86)

Masyarakat yang ingin bertamu mengucapkan salam, mengetuk pintu dan memanggil tuan rumah sewajarnya. Mereka tidak memasuk rumah jika belum diberi izin dari tuan rumah. Berbicara dengan bahasa yang sopan. Masyarakat Tiyuh Panaragan jika bertamu sudah selesai mereka selalu permisi kepada tuan rumah tidak semena-mena pulang tanpa seizin tuan rumah. adapun adab tuan rumah dimasyarakat Tiyuh Panaragan yang menerima tamu adalah: pertama Masyarakat Tiyuh Panaragan terlihat biasanya bila ada yang berkunjung atau bertamu, tuan rumah menyambut tamu dengan ikhlas, sopan, dan ramah terhadap tamu. Kedua Tuan rumah juga menyuguhkan makanan ringan yang sesuai dengan kemampuan tuan rumah. Ketiga Memuliakan tamu, dan selalu ramah dalam berbicara dengan tamu, selalu merespon pembicaraan tamu dengan serius. Kempat Kebiasaan masyarakat Tiyuh Panaragan juga, jika tamu pulang maka wajib bagi tuan rumah mengantarkan tamu hingga keluar rumah atau didepan pintu sebagai bentuk penghormatan tuan rumah kepada tamu.

Implementasi Nemui Nyimah dimasyarakat Tiyuh Panaragan dapat disimpulkan bahwa masyarakat Tiyuh Panaragan masih menerapkan budaya Nemui Nyimah dilihat dari penerapan silaturahmi dalam kehidupan sehari-hari, seperti keramah tamahan terhadap tamu, menyuguhkan makanan sesuai dengan kemampuan, sifat tersebut menonjol dalam kegiatan silaturahmi dalam masyarakat Tiyuh Panaragan. Masyarakat Tiyuh Panaragan masih memegang teguh budaya menghargai antar sesama, sopan santun, bermurah hati terhadap sesamasikap kepedulian sosial dan sebagainya. Prinsip Nemui Nyimah ini tidak hanya diberlakukan antar sesama manusia, tetapi untuk semua lapisan jagat raya, maka dari itu budaya Nemui Nyimah bukan hanya untuk suku Lampung saja tetapi untuk masyarakat umum, karena Nemui Nyimah merupakan 
kebudayaan lama dan asli kekayaan budaya bangsa yang sangat potensial terhadap pengembangan kebudayaan nasional, yang mencerminkan nilai yang khas dimiliki masyarakat Lampung.

Berdasarkan kesimpulan di atas implementasi budaya Nemui Nyimah dapat dilihat dalam penerapan silaturahmi, dimana adab-adab bertamu dan menerima tamu yang sesuai dengan ajaran Islam. Di dalam bertamu ataupun menerima tamu diajarkan bagaimana cara berbicara sopan santun terhadap tamu atau pun tuan rumah, bagaimana keramahtamahan dalam menerima tamu. Nemui Nyimah jika diterapkan dan dilestarikan dalam kehidupan sehari-hari atau dalam kehidupan bermasyarakat maka akan menciptakan kerukunan dimasyarakat dan toleransi terhadap sesama serta saling menghargai. Berdasarkan implementasi nilai-nilai pendidikan Islam dalam Nemui Nyimah di masyarakat Tiyuh Panaragan menunjukkan adanya nilai-nilai pendidikan Islam di dalamnya. Seperti terdapat di penerapan Nemui Nyimah yakni silaturrahmi memiliki tatacara atau adab-adab bertamu dan menerima tamu yang selaras dengan ajaran-ajaran Islam.

\section{SIMPULAN DAN SARAN}

Berdasarkan hasil Studi dan pembahasan tentang nilai-nilai pendidikan Islam dalam budaya Nemui Nyimah di masyarakat Lampung Pepadun, maka dapat diambil kesimpulan bahwa: Implementasi budaya Nemui Nyimah dimasyarakat Tiyuh Panaragan dapat dilihat dari hal-hal berikut: musyawarah, forum mulei menganai (bujang gadis), dan yasinan yang selalu dilaksanakan oleh masyarakat Tiyuh Panaragan. Implementasi budaya Nemui Nyimah dimasyarakat Tiyuh Panaragan terlihat dalam kegiatan silaturahmi, seperti terdapat tatacara atau adab-adab bertamu dan menerima tamu.

Setelah memperhatikan hasil Studi di atas, peneliti memberikan saran yang kiranya bermanfaat tentang nilai-nilai pendidikan Islam dalam budaya Nemui Nyimah di masyarakat Lampung Pepadun yaitu masyarakat Tiyuh Panaragan agar terus menjaga dan mempertahankan budaya Nemui Nyimah karena budaya tersebut sesuai dengan ajaran-ajaran Islam dan hendaknya Pemerintah Daerah agar dapat selalu mendukung masyarakat dalam upaya melestarikan nilai-nilai budaya Lampung (Sada, 2016). 


\section{DAFTAR PUSTAKA}

Achmadi. (2005). Ideologi Pendidikan Islam; Paradigma Humanisme Teosentris (Cet. 1). Yogyakarta: Pustaka Pelajar.

Amaliah, D., Sariyatun, S., \& Musaddad, A. (2018). Values of Piil Pesenggiri: Morality, Religiosity, Solidarity, and Tolerance. International Journal Of Multicultural and Multireligious Understanding (IJMMU), 5(5), 179-184.

Arifin. (2011). Ilmu Pendidikan Islam. Jakarta: Bumi Aksara.

Arikunto, S. (2002). Prosedur Penelitian Suatu Pendekatan Praktek. Jakarta: Rineka Cipta.

Fathurahman, P. (2011). Metode Penelitian Pendidikan. Bandung: Pustaka Setia.

Hidayat, D. (2014). Representasi Nemui-Nyimah sebagai Nilai-Nilai Kearifan Lokal: Perspektif Public Relation Multikultur. Jurnal Ilmu Komunikasi, 5(1), 90-102.

Irianto, S., \& Margaretha, R. (2011). Piil Pesenggiri: Modal Budaya dan Strategi Identitas Ulun Lampung. Makara, Sosial Humaniora, 15(2), 140-150.

Juwita, D. T., Cahyono, A., \& Jazuli, M. (2017). Nilai-Nilai Piil Pesenggiri pada Tari Melinting di Desa Wana Lampung Timur. Catharsis: Journal of Arts Education, 6(1), 82-90.

Kesuma, T. A. R. P., \& Cecilia, D. (2017). Piil Pesenggiri: Strategi Resolusi Konflik Menggunakan Nilai-Nilai Agama dan Pancasila. Jurnal Masyarakat \& Budaya, 19(2), 237-252.

Kountour, R. (2004). Metode Penelitian. Jakarta: Taruna Grafika.

Kurniawan, R. C. (2017). Piil Pesenggiri: A Concept of Political Power in Lampung Culture. Jurnal Ilmu Sosial dan Ilmu Politik, 21(1), 74-86.

Minandar, C. A. (2018). Aktualisasi Piil Pesenggiri sebagai Falsafah Hidup Mahasiswa Lampung di Tanah Rantau. SOSIETAS, 8(2), 517-526.

Moleng, L. J. (1977). Metodologi Penelitian Kualitatif. Bandung: Remaja Rosdakarya.

Muzakki, A. (2017). Memperkenalkan Kembali Pendidikan Harmoni Berbasis Kearifan Lokal (Piil Pesenggiri) pada Masyarakat Adat Lampung. Jurnal Penelitian Keagamaan dan Kemasyarakatan, 30(3), 261-280.

Nurdin, A. F. (2009). Integralisme Islam dan Nilai-Nilai Filosofis Budaya Lokal pada Pembangunan Propinsi Lampung. UNISIA, XXXII(71), 81-97.

Pairulsyah. (2013). Kualitas Pelayanan Publik Samsat Lampung dalam Perspektif Budaya Piil Pesenggiri. Fiat Justisia Jurnal Ilmu Hukum, 7(2), 168-180.

Roveneldo. (2017). Prosesi Perkawinan Lampung Pepadun: sebagai Bentuk Pelestarian Bahasa Lampung Lampung Pepadun Custom Marriage Procession: As a Form of Lampung Language Conservation. Ranah: Jurnal Kajian Bahasa, 6(2), 220- 
234.

Sada, H. J. (2016). Manusia dalam Perspsektif Agama Islam. Al-Tadzkiyyah: Jurnal Pendidikan Islam, 7(1), 129-142.

Sarbini, A., \& Khalik, A. T. (2010). Budaya Lampung Versi Adat Megou Pa' Tulang Bawang. Yogyakarta: Filsafat UGM.

Siswanto, E., Riyanto, A., \& Bestari, P. (2014). The Cultural Preservation of Piil Pesinggiri in Lampung Muliticutural Society: Citizenship Education Study in Baradatu, Waykanan Pelestarian Budaya Piil Pesinggiri Pendidikan Kewarganegaraan. Jurnal Pendidikan Kewarganegaraan, 18(2), 140-160.

Sugiyono. (2005). Metodelogi Penelitian Kuantitatif Kualitatif R\&D. Jakarta: Alfabeta.

Sugiyono. (2010). Metode Penelitian Pendidikan. Bandung: Alfabeta.

Yusuf, H. (2010). Dimensi Aksiologis Filsafat Hidup Piil Pesenggiri dan Relevansinya terhadap Pengembangan Kebudayaan Daerah Lampung. Jurnal Filsafat, 20(3), 281-302.

Yusuf, H. (2016). Nilai-Nilai Islam dalam Falsafah Hidup Masyarakat Lampung. Kalam: Jurnal Studi Agama dan Pemikiran Islam, 10(1), 167-192. 